\title{
Reactivation of headframes
}

\author{
S. Niederhagemann \\ Deutsches Bergbau-Museum [DBM], Informationssysteme, Germany
}

\begin{abstract}
Headframes take a special part among the industrial plants of the mining industry. Positioned at a central point of the production flow and often visible from far away, they were already the representatives of the mining company at the time of their erection. At present, the shutdown of all coal mines in Germany is politically aimed and production has reduced to fewer and fewer locations. A lot of closed mines are already demolished and the former mining areas have been transferred to a new use. Often only the headframes are preserved. They are maintained to remind people of the industrial history and the development of the region. Some headframes were added to the monument list. Some monument operators decided to bring the construction into a new use. The headframes differ in type of building, material, condition, construction and building method. The differences are regionally and historically conditioned. It is necessary to understand the construction method and the technology if a new concept of use has to be carried out. To keep the characteristics of a monument, the original function of the construction must be cognisable. Nevertheless, structural adjustments are sometimes necessary. This paper shows some examples of newly used headframes and demonstrates the conflict between preservation and new use.
\end{abstract}

Keywords: mining, headframe, rehabilitation.

\section{Introduction}

Headframes were originally constructed to carry the cable sheaves which redirect the hoisting cable from the machine into the mining shaft [1]. With the decline of Europe's mining industry a huge number of these support structures disappeared. Even after the closure of the collieries these structures have a special relevance to their regions. They are a symbol of the economic development and have contributed until today to the identity of the local population. 
The hoist constructions of the mining industry were designed to resist all loads until the crack of the hoisting cable [2, 3]. These enormous loads are in most cases no longer stressing the constructions, so first of all the stability against collapse is very high if there are no damages in the structure. Measures to increase the stability are only necessary if there are damages in the structure or if the new use needs a superstructure.

\section{Examples of new use}

For the new use of a headframe, the height of the structure plays an essential role. It also makes a significant difference whether a facility is made public, must remain locked or is used only by small guided groups. A close coordination with the security authorities and the fire service is recommended. Sometimes, the equipment of the rescue forces is decisive to the extent of required constructive measurements.

\subsection{Landmark}

In the case that no new use for a headframe could be found or the pecuniary resources are insufficient, the use is limited to the pure symbolic value of the plant. In such cases, it is often not possible to secure all areas sufficiently. Persons who enter into old industrial sites are not always aware of the dangers that lurk on them. In order to avoid bodily injury, these plants have to be closed off. A plant that is preserved only because of the symbolic relevance causes the least costs. Sometimes the costs for maintenance can already be reduced if parts of the plant can be demolished. These kinds of plants only remain their quality if they are seen from far away. In the silhouette of the city or countryside, the construction is still present and helps to get recognition for the former appearance.

In some cases, institutions or companies use the high symbolic and historical value of an old headframe in reconstructing it into an office building or a meeting room. In other cases the old structures are integrated a new building periphery. Examples of such a practice are numerous. In such a procedure the industrial monument is taken from its functional context. These objects have a need for an extensive explaining of the construction history for the visitor to understand the functioning. Also the constructive additions must be clearly visible for everyone.

\subsection{Viewing platform}

The support structures are visible from afar. A use as a viewing platform in such cases is obvious, and useful. With this new usage the planer must pay special attention to the safety of visitors. The accessibility to the upper sections of the construction has originally been designed for maintenance and repair purposes only. The simple stairways are not qualified for the needs of varying visitor groups. In particular, the use by children requires an improvement of the design 


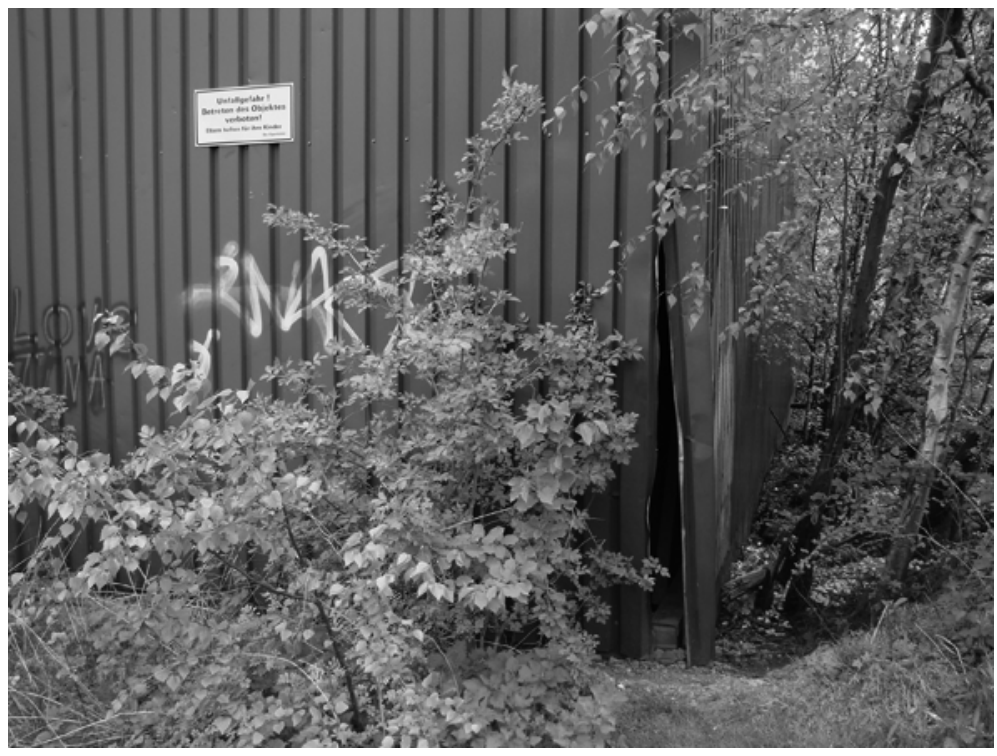

Figure 1: $\quad$ People always find a way into industrial plants.

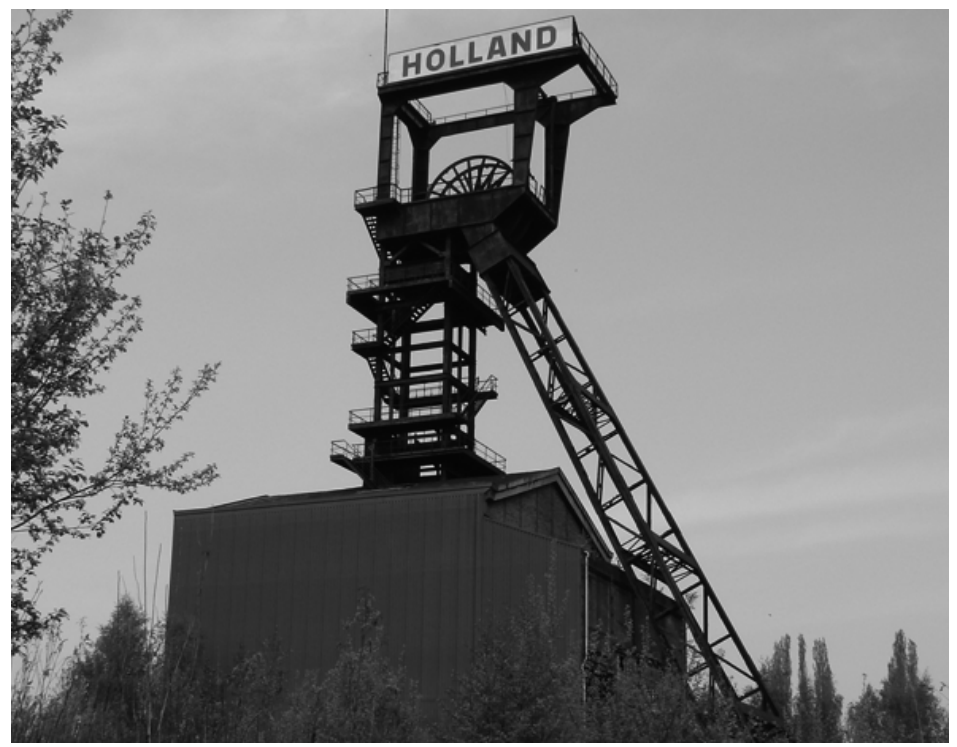

Figure 2: $\quad$ Headframe of Holland IV. 
for example on the railings. The DBM counselled the council authorities in the rehabilitation of the headframe of the former Holland IV shaft in Bochum, Germany. The construction was designed by the architectural firm Schupp and Kremmer initially for the shaft 4 in Zollverein Essen and at the end of the 1950s relocated to its current location. Also the neighbouring administrative and washing buildings are still preserved and include today a technology centre [4]. The owner of the headframe aspires an opening to the public. In such a case, the safety standards have to be particularly high, because the access cannot be restricted anymore. There might also be no persons who can intervene in the case of emergency.

Another example of a conversion of a former headframe to a viewing platform is the steel made construction of the former pit Prosper II in Bottrop. On behalf of the owner, the Foundation for Industrial Monuments, the DBM examines the possibilities for a reuse of construction and accompanies the following building measures. The DBM already investigated the rehabilitation works for the masonry tower below the headframe $[5,6]$. This steel construction was erected in 1934 above the masonry headframe from 1875. In the beginning there was only one level for the cable sheaves. In 1958 a second level was added to the construction [7]. The shaft was started in 1871 and reached a maximum depth of $813 \mathrm{~m}$, which had been completely filled by 1987 [8].

Discussions with the fire department showed that the accessibility to the platform through the inner structure of the masonry tower was not permitted because of high fire loads. The level of the cable sheaves must have a separate fire protection access. The approaches had to be done so that people on the headframe, regardless of the situation in the masonry tower can be saved. It should be noted that the local fire brigade turntable ladder has a maximum height of $30 \mathrm{~m}$. The platform is about $40 \mathrm{~m}$ above the ground.

For conservation reasons, we decided to partly reactivate the old escape routes of the miners. In the 1980s these staircases were backfilled with hydraulic mortular for stability reasons. The backfill reaches from the bottom of the construction to a height of about $20 \mathrm{~m}$. Unfortunately these areas are no longer available. In the upper sections the stairs are still intact. These stairs were never accessible to the public before. The public were these stairs have not been accessible. This typical emergency exit of the Malakofftower is shown nowhere else.

For an opening to the public the existing stairs were unsuitable. The previous designs were made to give access to a trained worker for maintenance purposes. This was no oncoming traffic. To improve the facility for groups with children it was necessary to partial replace some already heavily damaged stairs. To keep the monument's appearance the old route has been kept. The original stairs had a width of $80 \mathrm{~cm}$. The standards demand a 1,2 $\mathrm{m}$ stairway in public areas. This would hardly change the appearance of the headframe. In accordance with the council the stairs will get only get a $1 \mathrm{~m}$ with. To compensate this, the size of visitor groups is limited to 20 persons and the group is assisted by safety trained guide. 

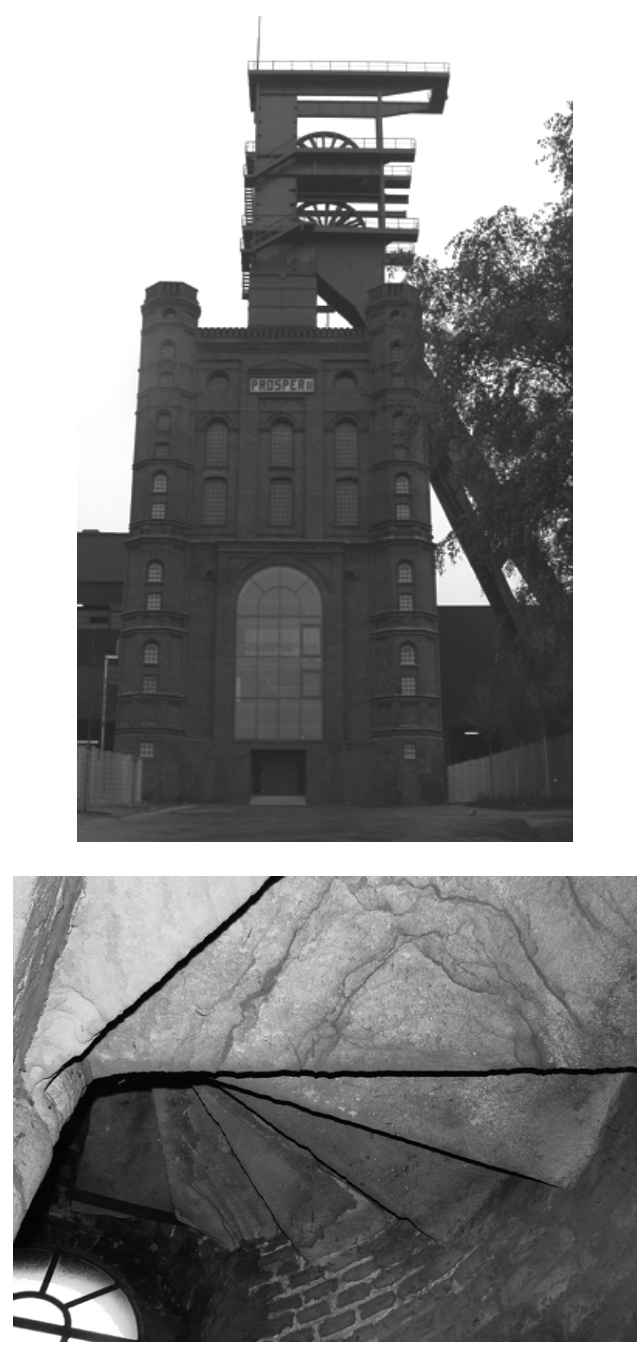

Figure 3: Headframe of Prosper II and staircase inside the tower corner.

\subsection{Museum/exhibition}

In regions with only few mining remains the usage as a museum is often preferred. The headgear above the former shaft Germania in Dortmund Germany is today used as the biggest museum exhibit of the German Mining Museum. Just like the headgear of Holland IV, the headgear of Germania was designed by the architectural firm Schupp and Kremmer. It was erected in 1944 for a double hoist. The steel construction has a weight of about $850 \mathrm{t}$ and a height of 71,40 m. At the time of the erection this headgear was the most powerful and modern one in Germany. The mining lasted until 1971. In 1973 the construction was 


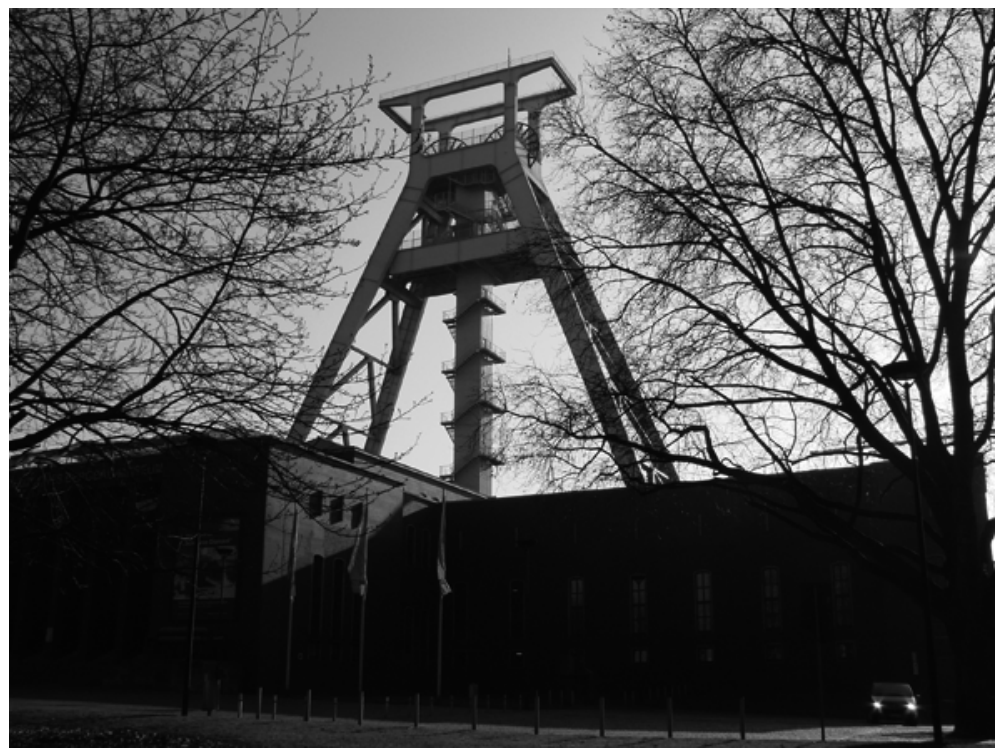

Figure 4: Headframe of Germania at the German Mining Museum.

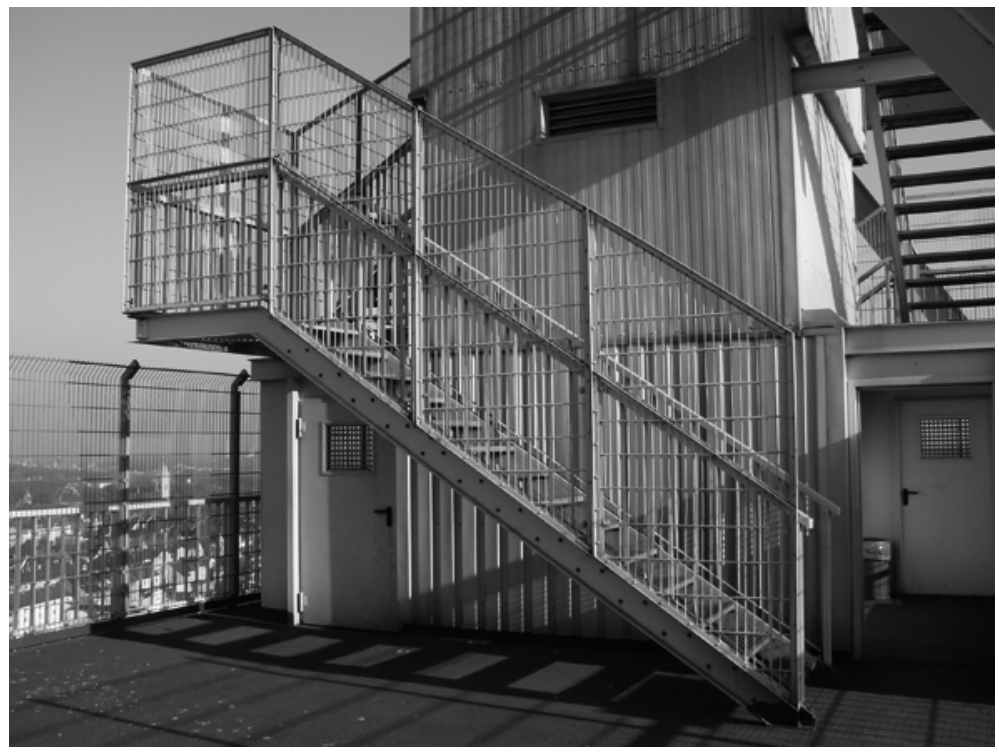

Figure 5: Railing at the headframe of the German Mining Museum. 
transported to the town of Bochum above the existing building of the Museum. For that transportation it was separated into pieces of 30 tons each and puzzled together again in the neighbouring town. For this work only 20 days were needed [9]. Visitors of the German Mining Museum get onto the top by a standard elevator. From the first level they can walk upwards through a staircase. The visitor can move without accompaniment, so is the security standard has to be very high. Close lattice prevent the people from falling down the construction. In the case of an elevator failure, the visitors are picked up by staff. All persons are guided down via the original stairs into a secure staircase inside the museums building. The visiting of the headframe is only possible during the museums opening hours and under supervision of the staff. To open the stairs for visitors it would be necessary to improve the construction.

\section{Outlook}

The old headframes are essential landmarks. The maintenance is important for the identity because they illustrate the industrial history of many regions. The number of sustainable museums is limited. To preserve these important cultural monuments, it is therefore necessary to find new ways of preservation and use concepts.

\section{References}

[1] Schönberg, Heinrich: Die technische Entwicklung der Fördergerüste und türme des Bergbaus, in: Becher, Bernd; Becher, Hilla: Die Architektur der Förder- und Wassertürme, München 1971, S. 245-324, Zugl.: Aachen, Techn. Hochschule, Diss., 1970.

[2] NORM DIN 4118 June 1981: Fördergerüste und Fördertürme für den Bergbau, Lastannahmen, Berechnungs- und Konstruktionsgrundlagen.

[3] Möhrle, Theodor: Das Fördergerüst, seine Entwicklung, Berechnung und Konstruktion, 2. Auflage, Berlin 1928.

[4] Regionalverband Ruhr, Route Industriekultur, www. routeindustriekultur.de, accessed on 15 April. 2009

[5] Niederhagemann, Stefan: the reactivation of a historic shaft building, in: Brebbia, C.A.: Heritage Architecture VIII, p. 771-777, 2003

[6] Niederhagemann, Stefan: Die Reaktivierung des Malakoffturmes Prosper 2 in Bottrop, in: Der Anschnitt, 5-6 2004

[7] Historische Gesellschaft Bottrop: Ein Turm mit Vergangenheit und Zukunft, 1996

[8] Huske, Joachim: Die Steinkohlenzechen im Ruhrrevier, Bochum 2006.

[9] Slotta, Rainer: Das Fördergerüst, in: Slotta Rainer [editor]: 75 Jahre Deutsches Bergbau-Museum Bochum, p. 499-511, 2005 